\title{
ARTICLE
}

\section{Analysis of alternatives for radwaste management during dismantling of the equipment in building V1 at Ignalina NPP}

\author{
Povilas Poskas $^{\mathrm{a}}$, Gintautas Poskas ${ }^{\mathrm{a}, \mathrm{b}}$ * and Arunas Sirvydas ${ }^{\mathrm{a}}$ \\ ${ }^{a}$ Lithuanian Energy Institute, Kaunas, Lithuania, ${ }^{b}$ Kaunas University of Technology, Kaunas, Lithuania
}

\begin{abstract}
Ignalina NPP was operating two RBMK-1500 reactors. Unit 1 was closed at the end of 2004, and Unit 2 was closed at the end of 2009. Now preparation for dismantling activities, including building V1, is ongoing. Building V1 is located on the west side of Unit 1. It is a nine-level building with more than 200 rooms. Part of Unit 1 auxiliary systems are located in Building V1. Most systems in this building are contaminated. After situation analysis in Building V1 at Ignalina NPP and collection of the primary information related to the components' physical and radiological characteristics, location and other data, two alternatives for radwaste management during dismantling were formulated and evaluated: the first, when the decontamination of dismantled components is performed (where it is reasonable) and the second one, when no decontamination of dismantled components is performed and after dismantling the components are routed to appropriate waste storage or disposal sites. To select the preferable alternative, MCDA method - AHP (Analytic Hierarchy Process) was applied. Hierarchical list of decision criteria, necessary for assessment of alternatives performance, were formulated. Quantitative decision criteria for these alternatives were analyzed using software DECRAD, which was developed at Lithuanian Energy Institute Nuclear engineering laboratory. Qualitative decision criteria were evaluated using expert judgment. The results have shown that the first alternative (decontamination is performed) is better than the second one (no decontamination is performed).
\end{abstract}

Keywords: Ignalina NPP; RBMK-1500 reactor; dismantling; radwatse management; MCDA

\section{Introduction}

The Ignalina NPP is located in the north-eastern part of Lithuania, near the borders of Latvia and Belarus. The Ignalina NPP was operating two RBMK-1500 reactors (graphite moderated). Unit 1 and Unit 2 were closed at the end of 2004 and at the end of 2009 respectively. So, now preparation for the dismantling of the systems is ongoing.

In this paper, the analysis of different radwaste management alternatives during the dismantling of Building V1 equipment at Ignalina NPP, where waste streams, safety and environmental criteria are added to the usual economic, technical, duration and social criteria, is presented. The traditional single decision-making approach is no longer able to handle these problems. The multiplicity of criteria and the involvement of several decision makers in the decision procedure make multi-criteria decision analysis (MCDA) a valuable tool.

\section{Methodology}

Part of Unit 1 auxiliary systems are located in

*Corresponding author. Email: g.poskas@gmail.com
Building V1: a part of the reactor's gas circuit, gas discharges purification system, the main circulation circuit maintenance cooling tanks system, a part of the emergency core cooling system and different components of ventilation systems. It is a nine-level building with more than 200 rooms and with equipment of about 1300 tones in mass.

Based on radiological characterization results, V1 Building components could be classified as very low level waste (VLLW), exempt waste (EW) and low/intermediate level waste (L/ILW) with sealed spend sources (SSS), which ratios are $60 \%, 39 \%$ and less than $1 \%$ respectively.

Not all systems in the building can be dismantled at the same time. Some of them are still necessary for safety purposes in Unit 1 and will be also needed for safety assurance during the dismantling. Thus, the dismantling works are divided into three phases.

Phase 1 was planned to start in 2012 (but there is some delay in the schedule), Phase 2 in 2023, (during the dismantling of the systems in reactor building) and Phase 3 after the destruction of Building V1.

\subsection{Quantitative data calculation tool - DECRAD}

In this paper, to analyse different equipment 
dismantling alternatives in Building V1, DECRAD tool [1] was used (developed at Lithuanian Energy Institute by Nuclear Engineering Laboratory). It is composed of calculation of the necessary data for the assessment of different alternatives to support detailed dismantling projects and to plan the disposal of integrated waste for whole nuclear facilities or separate buildings.

DECRAD is used to register and evaluate all the data required for $\mathrm{D} \& \mathrm{D}$ activity planning. Some outputs are: doses, discharges, waste activity, costs, inventory, radiological data, waste management and scheduling data, data flows, etc.

In order not to operate with each single component, all components in equipment technical data list were grouped into waste streams. Such approach allowed to group/generalize the types of equipment/components with the same features.

\subsection{MCDA technique}

Analytic Hierarchy Process (AHP) method was chosen for the analysis of equipment dismantling alternatives in Building V1 [2].

AHP is applied by breaking down an unstructured problem into hierarchical structures. Criteria weights and qualitative data are evaluated by decision-makers using pair-wise comparisons and eigenvectors to determine which variables have the highest priority.

Calculations were performed using a commercial software, i.e. MATLAB and MS EXCEL.

\subsection{Alternatives}

Two radwaste management alternatives during the dismantling of Building V1 equipment were formulated:

A1 - mechanical decontamination (vacuum blasting) is performed for contaminated dismantled components if it is possible. They are decontaminated to EW level. The secondary waste and components that cannot be decontaminated to EW level, are either disposed at the VLLW repository, or transported to the treatment facility for further treatment and disposal in the near surface disposal facility for L/ILW;

A2 - mechanical decontamination of the contaminated dismantled components is not performed. VLLW is disposed into VLLW repository while L/ILW is transported to the treatment facility for further treatment and disposal in the near surface disposal facility for L/ILW.

\subsection{Criteria}

Table 1. Fragment of criteria tree to measure dismantling alternatives performance in Building V1.

\begin{tabular}{|c|c|c|c|}
\hline Criteria & Sub-criteria & Type & Units \\
\hline $\begin{array}{c}\text { W1.Waste } \\
\text { streams }\end{array}$ & W1.1. Primary waste ratio & $\begin{array}{c}\text { Quanti } \\
\text { tative }\end{array}$ & $\%$ \\
\cline { 2 - 3 } & \multicolumn{3}{|c|}{ W1.2. Secondary waste ratio } \\
\hline \multirow{2}{*}{ S2. Social } & S2.1. Employment level & $\begin{array}{c}\text { Qualit } \\
\text { ative }\end{array}$ & $\begin{array}{c}\text { Expert } \\
\text { jud. }\end{array}$ \\
\cline { 2 - 3 } & S2.2. Burden level &
\end{tabular}

Qualitative and quantitative criteria tree consisting of 5 criteria groups (waste streams, economic, duration, safety, technology, environmental and social) and 21 unique criteria were formulated to suit the needs of Building V1 (Table 1).

\section{Results}

\subsection{Quantitative data}

Waste streams analysis for alternative A1 in Phase 1 shows (Figure 1) that $79 \%$ of the primary waste meet EW criteria and will be transported to the free release management facility (FRMF). $6 \%$ of the primary waste must be disposed of to the VLLW repository. The rest part (15\%) of the primary waste can neither be decontaminated to the EW level, nor meets the requirements of the VLLW repository, so the waste must be transported to B3 complex (i.e. New Solid Waste Management and Storage Facilities) for further management and storage till the final disposal in the near surface repository (NSR).

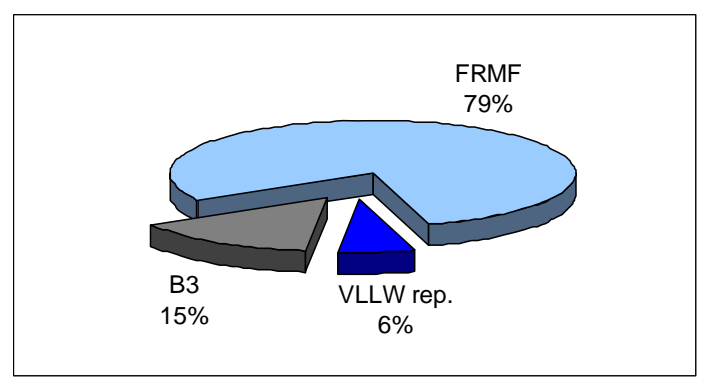

Figure 1. Waste streams in Phase 1 for alternative A1.

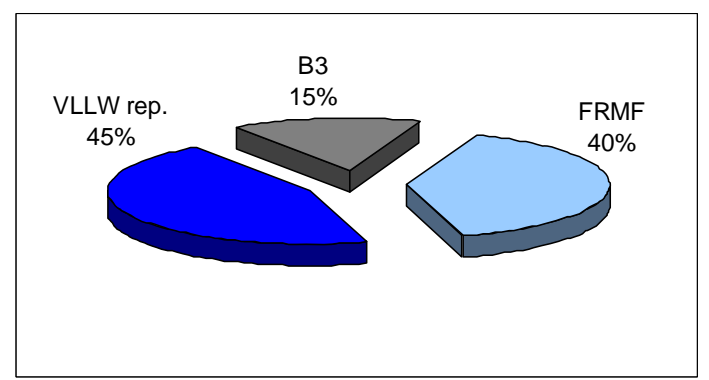

Figure 2. Waste streams in Phase 1 for alternative A2.

Waste streams analysis for alternative A2 in Phase 1 shows that only $40 \%$ of the overall dismantled waste mass will be managed as EW and will be transported to the FRMF (Figure 2). This amount of EW is two times smaller than in alternative A1. Primary waste amount to the VLLW repository is $45 \%$ (7,5 times bigger than in A1). In this case, the same amount of waste (15\%) is transported to the B3 complex.

Waste streams analysis has shown that during Phase 2 for A1 alternative, $98 \%$ (Figure 3 ) of the dismantled mass will be EW and only $2 \%$ of the primary waste will be transported to B3 and the VLLW repository.

For alternative A2 (Figure 4), $37 \%$ of the primary waste is EW (i.e. waste that are transportable to the 
FRMF), while applying decontamination this amount increases more than two times (98\%; Figure 3). Only $1 \%$ of the primary waste should be transported to the VLLW repository for alternative A1 while for alternative A2 the amount of such waste is $62 \%$ of the overall dismantled mass of the components.

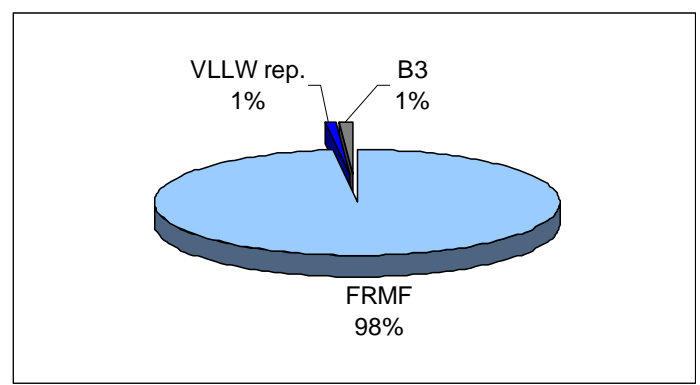

Figure 3. Waste streams in Phase 2 for alternative A1.

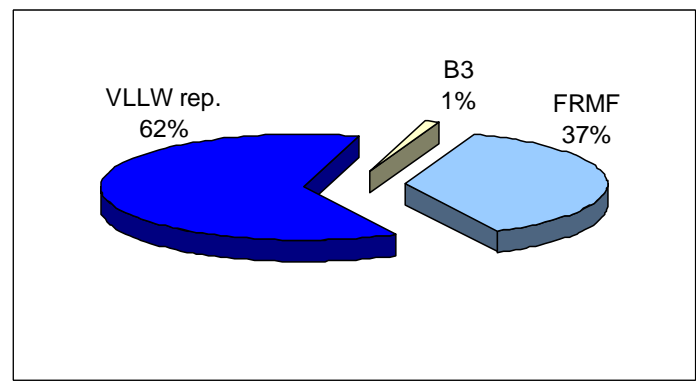

Figure 4. Waste streams in Phase 2 for alternative A2.

Apart from the primary waste, there will certainly be the secondary waste such as metal shaves, used cutting tools (saws, abrasive discs, etc.), filters, abrasive (during the mechanical decontamination), etc. Figure $\mathbf{5}$ demonstrates the distribution of the secondary waste masses by the disposal routes in both alternatives. The mass of the secondary VLLW is four times smaller if no decontamination is performed compared to the case when it is performed (100\% and $25 \%$ respectively), and the mass of L/ILW to B3 is only 1.7 times smaller (100\% and $58 \%$ respectively)..

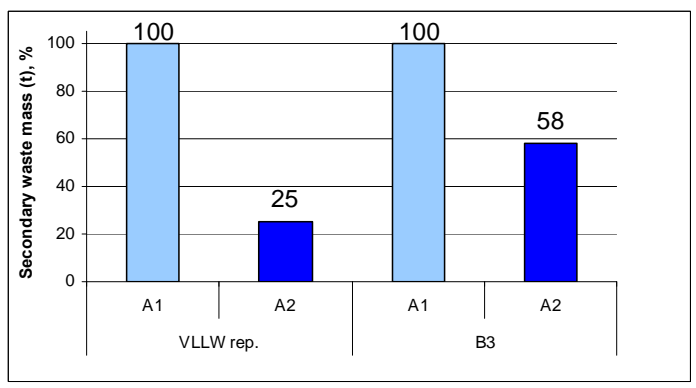

Figure 5. Secondary waste disposal ways for different alternatives.

Analysis of workers' collective doses has shown that in Phase 1 for alternative A1 doses are $14 \%$ higher. In Phase 2 collective doses are almost the same for both alternatives (Figure 6). This is because decontamination activities are mainly performed in Phase 1 .

After evaluating both alternatives it was defined that Phase 1 lasts longer than Phase 2. The difference is mostly determined by mass of the dismantled components that is $\sim 13 \%$ smaller in Phase 2 than in Phase 1.

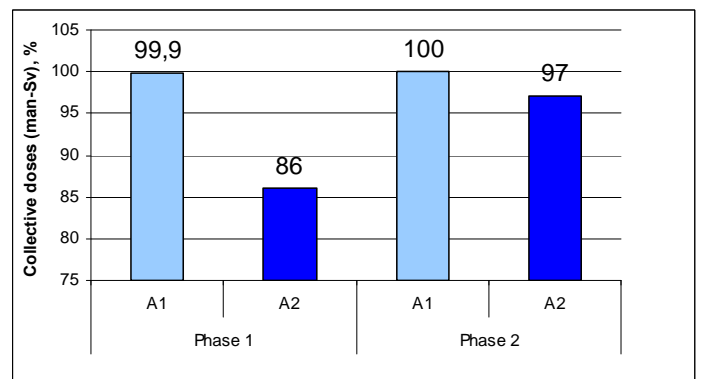

Figure 6. Workers' collective doses for different alternatives.

When decontamination is not performed (Figure 7; alternative A2), duration of Phase 1 is only $3 \%$ shorter in comparison to the case when decontamination is performed (Figure 7; alternative A1). This happens because decontamination of the components during alternative A1 is performed simultaneously with dismantling and thus, the duration of the project is almost the same. Also, minor ( $6 \%$ ) duration differences occur between the two alternatives during Phase 2. Obviously, duration of Phase 2 is shorter when no decontamination is performed (Figure 7; A2 alternative, Phase 2).

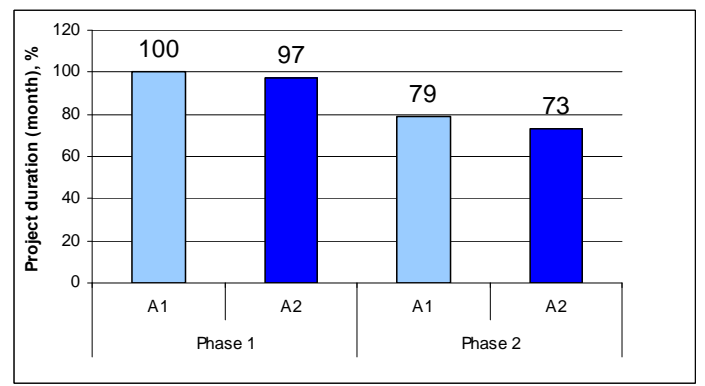

Figure 7. Project duration in months.

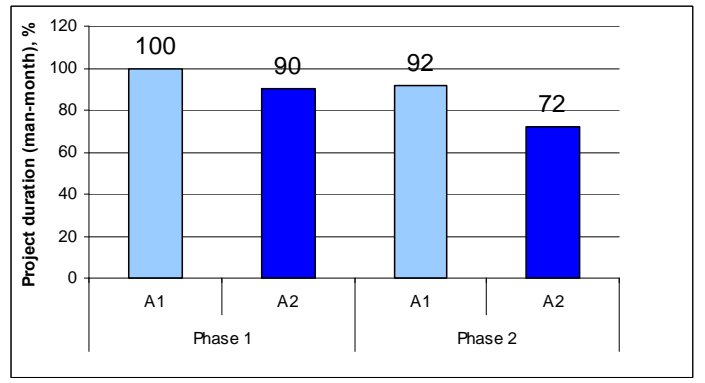

Figure 8. Project duration in man-months.

Figure 8 demonstrates the comparison of the project duration expressed as a man/month criterion. In this case, the duration is also shorter for alternative A2. The difference in this case between alternative A1 and 
alternative A2 is only $10 \%$ in Phase 1 and $20 \%$ in Phase 2.

The analysis of the investment necessary to purchase equipment for $D \& D$ activities has shown that when decontamination is not performed (alternative A2), the investments are only $6 \%$ lower compared to the case when decontamination is performed (A1 alternative).

The investments differ slightly because the price of the decontamination equipment (needed only for alternative A1) is very similar to the price for the half-height ISO containers for the dosposal of VLLW waste (more are needed for alternative A2).

The overall expenses for Phase 2 are considerably lower than those for Phase 1, because duration of Phase 2 is shorter than of Phase 1 and all the necessary equipment is purchased during Phase 1.

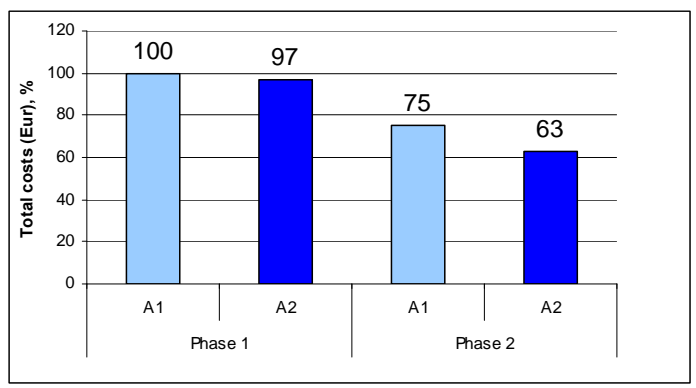

Figure 9. Total costs.

Figure 9 demonstrates that costs of alternative A2 in Phase 1 and Phase 2 are smaller than costs for alternative $\mathrm{A} 1$ ( $3 \%$ and $\sim 12 \%$ respectively).

\subsection{MCDA results}

AHP method was applied in this research. Five experts participated in the pair-wise comparisons of criteria, sub-criteria and alternatives performance against qualitative sub-criteria. Experts are not used to evaluate alternatives performance against quantitative sub-criteria, therefore normalized weights of quantitative sub-criteria values are calculated by DECRAD. Hierarchical structure for Expert 2 is shown in Figure 10.

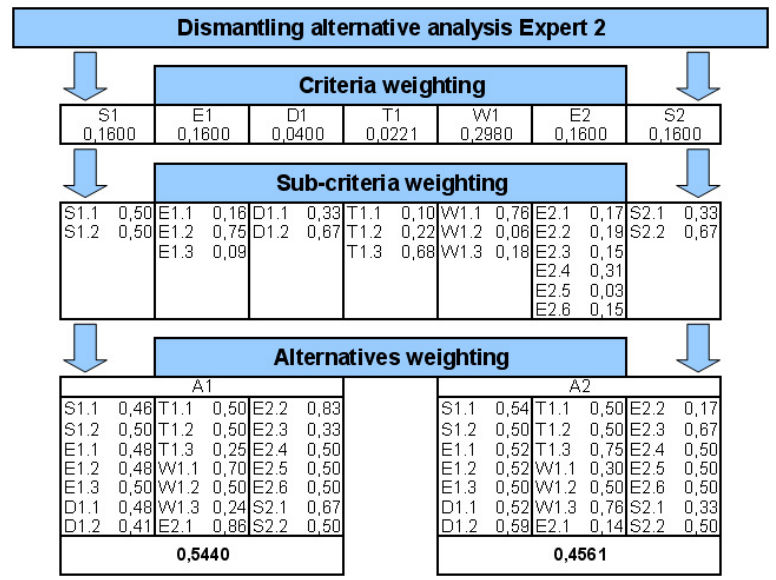

Figure 10. Hierarchical structure of AHP for Expert 2.
The final rank of the dismantling alternatives is calculated based on the expert's evaluations and results of DECRAD calculations (Figure 11).

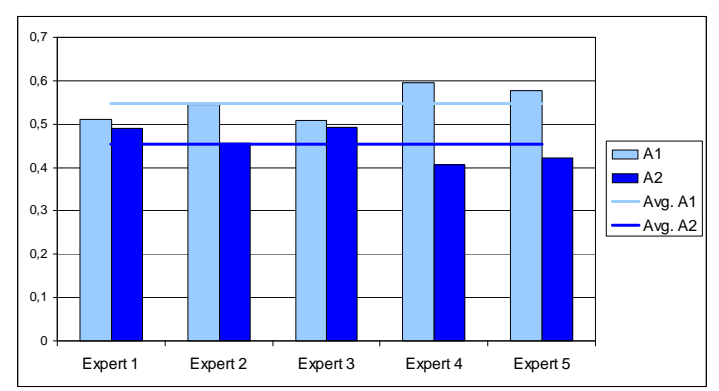

Figure 11. Final ranking of dismantling alternatives.

The assessment performed using the AHP method of Multi-Criteria Decision Analysis has shown that alternative A1 (decontamination is performed) with the 0.55 final score is better than alternative A2 (no decontamination is performed) with the 0.45 final score. Thus alternative A 1 is recommended as a better option for the dismantling of Ignalina's building V1 equipment when mostly very low level waste is generated.

\section{Conclusion}

After analysis of two alternatives for radwaste management during the dismantling of the equipment in Building V1, the following conclusions have been made:

1. In Phase 1 , the mass of primary exempt waste (EW) is almost two times higher when decontamination is performed (alternative A1) compared to the case when no decontamination is performed (alternative A2), $79 \%$ and $40 \%$ respectively. The mass of very low level waste (VLLW) is $6 \%$ when decontamination is performed and $45 \%$ if decontamination is not performed.

2. In Phase 2, the mass of primary EW is almost two times higher when decontamination is performed compared to the case when no decontamination is performed, $98 \%$ and $37 \%$ respectively. The mass of VLLW is $1 \%$ when decontamination is performed and $62 \%$ if decontamination is not performed.

3. Total duration of the project, investment necessary for the project and total project costs for both alternatives are similar (difference is less than $10 \%$ ).

4. The assessment performed using the AHP method of Multi-Criteria Decision Analysis has shown that alternative A1 (decontamination is performed) is better than alternative A2 (no decontamination is performed).

\section{References}

[1] A. Simonis, A. Sirvydas and G. Poskas, The Software DECRAD Validation report, TA-14-13.10. Lithuanian Energy Institute, Nuclear Engineering Laboratory, (2010).

[2] T. L. Saaty, Fundamentals of Decision-making and Priority Theory with the AHP, RWS Publications, Pittsburg, PA, USA, (1994). 